\title{
Diastasis of rectus abdominis muscles: patterns of anatomical variation as demonstrated by ultrasound
}

\author{
Antonio Corvino ${ }^{1 A, B, C, D, E, F, G}$, Dario De Rosa ${ }^{2 B}$, Carolina Sbordone ${ }^{3 B}$, Antonio Nunziata ${ }^{2 D}$, Fabio Corvino ${ }^{4 A, F}$, \\ Carlo Varelli ${ }^{2 G}$, Orlando Catalano $0^{2 A, B, C, D, E, F, G}$ \\ 'Department of Motor Science and Wellness, University of Naples "Parthenope", Naples, Italy \\ ${ }^{2}$ Radiology Unit, Istituto Diagnostico Varelli, Naples, Italy \\ 3Department of Medicine and Health Science, "Vincenzo Tiberio" Molise University, Campobasso, Italy \\ ${ }^{4}$ Department of Vascular and Interventional Radiology, Cardarelli Hospital, Naples, Italy
}

\section{Abstract}

Purpose: The aim of our study was to categorise the anatomical variations of rectus abdominis muscle diastasis (diastasis recti) by using ultrasound (US).

\begin{abstract}
Material and methods: In a one-year period 92 women were evaluated with US because of suspected diastasis of rectus muscles. Patients were examined in a supine position, with head extended, upper limbs aligned to the trunk, and knees flexed. US was performed with high-frequency, broad-band transducers. Trapezoid field-of-view and extended field-of-view were employed to measure diastasis exceeding $5 \mathrm{~cm}$. Diastasis was defined as a margin-to-margin distance $>20 \mathrm{~mm}$ at rest and classified according to the following anatomical patterns: open only above the navel, open only below the navel, open at the navel level, open completely but wider above the navel, and open completely but wider below the navel.

Results: Diastasis was found in 82 patients (30-61 years old, mean age 35 years). The width was 21-97 mm, mean $39 \mathrm{~mm}$. The prevalence and severity of the anatomical patterns was as follows: open only above the navel in $48 \mathrm{pa}-$ tients $(21-88 \mathrm{~mm}$, mean $40 \mathrm{~mm})$, open only below the navel in one patient $(33 \mathrm{~mm})$, open at the navel level in seven patients (23-39 mm, mean $34 \mathrm{~mm}$ ), open completely but wider above the navel in 24 patients $(21-97 \mathrm{~mm}$, mean $41 \mathrm{~mm}$ ), open completely but wider below the navel in two patients (21-29 mm, mean $25 \mathrm{~mm})$.

Conclusions: The above-navel patterns of recti muscle diastasis are the most common. Even when open completely, diastasis is usually wider above the navel. Knowledge of the anatomical type of rectus muscle diastasis could be of value to the patient (exercises to do and to avoid) and to the surgeon (abdominoplasty planning).
\end{abstract}

Key words: ultrasound, post-partum, rectus abdominis muscle, diastasis, abdominoplasty.

\section{Introduction}

Diastasis of abdominal wall recti muscles, i.e. the increase in width of the linea alba with a separation between the paired recti muscles above the normal distance, represents a very common occurrence, at least in the minor degrees of widening $[1,2]$. Though diastasis can be found in both sexes and at various ages of life, it typically represents a post-partum event [3]. Widening of the weakened linea alba can be as large as $20 \mathrm{~cm}$, with an inter-rectal distance greater than $5 \mathrm{~cm}$ being classified as severe [4]. Recti muscle diastasis is basically regarded as an aesthetic issue, with the subject presenting a bulging and flabby abdomen and looking as if they were "still pregnant". However,

Correspondence address:

Dr. Antonio Corvino, Department of Motor Science and Wellness, University of Naples “Parthenope", via F. Acton 38, I-80133 Naples, Italy,

e-mail: an.cor@hotmail.it

Authors' contribution:

A Study design · B Data collection · C Statistical analysis · D Data interpretation · E Manuscript preparation · F Literature search · G Funds collection 
a number of intra-pregnancy post-partum impairments have been somehow linked to this abnormality, including back pain, abdominal pain, and incontinence [5-7]. Risk factors for developing post-partum diastasis are believed to include patient age above 35 years, foetal macrosomia, twin pregnancy, and history of previous pregnancies $[2,6,7]$. Caesarean section seems not to be a risk factor, compared to spontaneous delivery, although according to some studies the risk of developing diastasis is higher after a Caesarean section [2]. Conversely, the antepartum activity level may have a protective effect on recti muscle diastasis, and exercise may improve post-partum symptoms of diastasis [1].

Recti muscle diastasis is usually identified clinically, or even by patient auto-evaluation. However, clinical assessment can be difficult when the subcutaneous layer is particularly thick [8,9]. Additionally, an accurate and objective measurement of the separation is mandatory to plan the appropriate management. Ultrasound (US) is commonly employed in the assessment of the anterior abdominal wall abnormalities [10-13]. Being a non-invasive and repeatable imaging modality $[14,15]$. US is regarded as the imaging modality of choice in the initial assessment of recti muscle diastasis, although plastic surgeons usually require also a computed tomography (CT) or a magnetic resonance imaging (MRI) study in patients scheduled for surgical repair with abdominoplasty.

The purpose of this single-centre, prospective study was to categorise the different anatomical variations of the rectus abdominis muscles diastasis by using US. To our knowledge, no published series has evaluated this issue of rectus muscle diastasis.

\section{Material and methods}

\section{Study population}

The study was approved by our Institutional Review Board. All enrolled patients gave their informed consent. Between May 2018 and April 2019 there were 92 consecutive women referred to our US laboratories because of a suspicion of diastasis recti. Patients had been referred for US by their plastic surgeon, family doctor, or gynaecologist. Many patients were self-referred. None of the women was pregnant at the moment of the examination, and none had abnormalities of the abdominal wall (deforming surgical scars, extensive fibrosis, etc.) that could interfere significantly with the US measurement. Sometimes a belly that is too flabby may be an obstacle to correct measurement, but no cases in our study had be excluded for this reason. The following data were recorded: patient age, parity, number of previous pregnancies, modality of delivery (spontaneous versus Caesarean section), and time since last delivery. There were also some males evaluated in the same period, but these were excluded to improve uniformity of the study populations.

\section{Examination protocol}

Studies were performed by two operators, with 33 and 13 years of experience with US, respectively. Operators had a specific training in evaluating diastasis recti. Voluson E8 (GE Healthcare) and RS85 (Samsung Healthcare) scanners were employed. US scans were performed with high-frequency, broad-band linear transducers. Transducer frequency could be adapted according to the thickness of the subcutaneous layer, but it was typically $10 \mathrm{MHz}$. Harmonic imaging was employed whenever necessary, particularly when the border of the rectus muscle did not appear to be sufficiently sharp. Patients were placed in the supine decubitus, with the head slightly extended above a pillow, the upper limbs aligned to the trunk, and the knees slightly flexed.

Measurements were obtained at rest, in a neutral moment immediately after an expiration. We accurately avoided pressing excessively on the abdominal surface with this transducer, to avoid pressure-related contraction reflexes. The typical level of the transverse scan of the abdominal wall was $3 \mathrm{~cm}$ above the navel and $2 \mathrm{~cm}$ below the navel, but the entire of the midline was checked to identify the exact pattern of diastasis. The inter-rectal width, i.e. the margin-to-margin distance between the medial border of the two rectus muscles, was recorded. At each of the two levels, the measurement was repeated three times by a single operator and then the mean value was collected. In the case of a diastasis exceeding $4 \mathrm{~cm}$ we employed trapezoid field-of-view scans to measure, while in the case of diastasis above $5 \mathrm{~cm}$ we employed real-time, extended field-of-view reconstructions. Measures obtained through an extended field-of-view image have proven to be fully comparable to those obtained on a conventional US image (Figure 1) [16]. In our practice we also routinely check the abdominal wall midline, both at rest and during the Valsalva manoeuvre, to rule out any concomitant hernia. However, this aspect is beyond the focus of this study.

We also reviewed the data regarding diastasis severity from the non-contrast enhanced CT studies (64-detector row scanner) studies and non-contrast enhanced MRI (1.5T scanner) studies in patients who also underwent cross-sectional imaging.

\section{Data analysis}

All measures were taken three times, and the mean value was recorded. Diastasis was defined as a margin-to-margin distance of more than $20 \mathrm{~mm}$. Diastasis was classified according to the following five anatomical patterns: open only above the navel, open only below the navel, open at the navel level, open completely but wider above the navel, open completely but wider below the navel.

\section{Results}

Diastasis was found in 82 patients, representing the $89.1 \%$ of the study population. The 82 patients with diastasis 

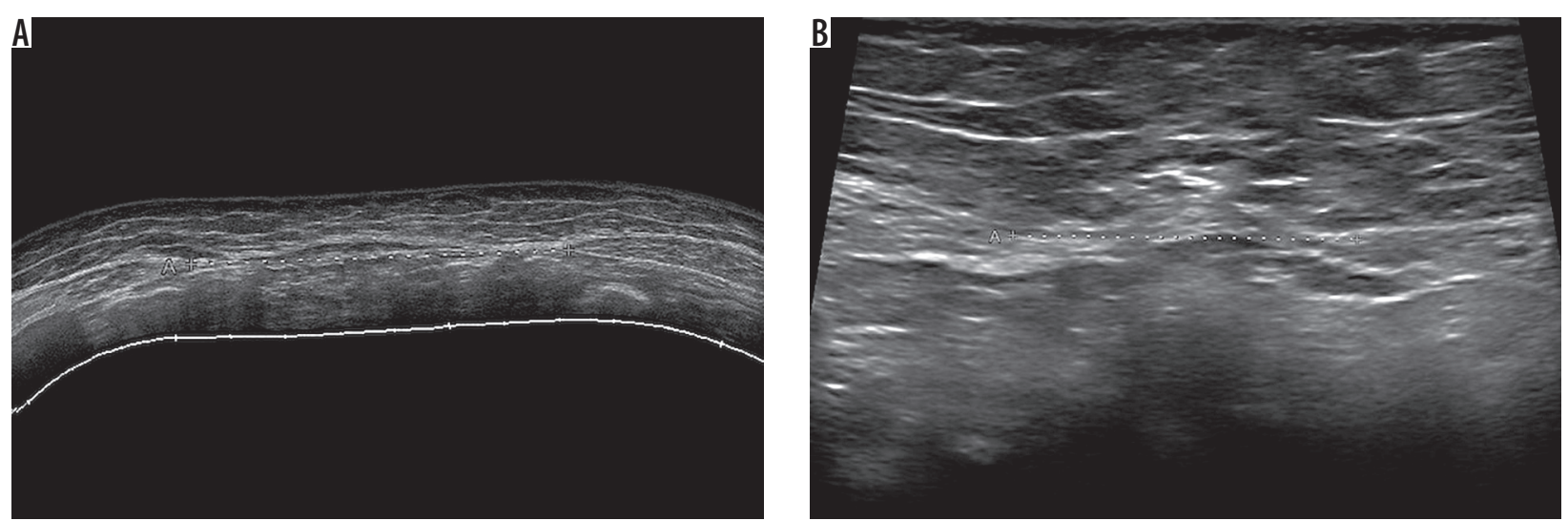

Figure 1. Thirty-two-year-old woman with two previous pregnancies. Diastasis (callipers) is present both above the navel (69 mm, extended field-of-view image in $\mathrm{A}$ ) and below the navel ( $30 \mathrm{~mm}$, conventional field-of-view image in B)

had an age range between 30 and 51 years, with a mean age of 35 years. There were five nulliparous women and 77 women with history of previous pregnancies. These ranged from one to four pregnancies, mean 1.9. Among 149 deliveries, there were 91 spontaneous deliveries and 58 Caesarean sections. Time from last delivery was 8-62 months, mean 14 months. Last delivery was spontaneous in 48 out of 77 women history of pregnancies and through Caesarean section in 29 (Table 1).

The separation width ranged between 21 and $97 \mathrm{~mm}$, with a mean value of $39 \mathrm{~mm}$. The following prevalence and severity of the various anatomical patterns was found. Open only above the navel in 48 cases $(58.5 \%$; $21-88 \mathrm{~mm}$, mean $40 \mathrm{~mm}$ ). Open only below the navel in one case $(1.2 \% ; 33 \mathrm{~mm})$. Open at the navel level in seven cases (8.5\%; 23-39 mm, mean $34 \mathrm{~mm})$. Open completely but wider above the navel in 24 cases $(29.3 \%$; $21-97 \mathrm{~mm}$, mean $41 \mathrm{~mm}$ ). Open completely but wider below the navel in two cases $(2.4 \% ; 21-29 \mathrm{~mm}$, mean $25 \mathrm{~mm}$ ) (Table 2, Figure 2). In many of the cases with diastasis present only or more largely above the navel level, the distance between the two recti muscles measured below the navel was not only below the $20 \mathrm{~mm}$ threshold but was also close to zero, without any visible gap between the muscles.

There was no significant correlation between last delivery type and the pattern of diastasis. Comparing the only two groups with sufficient numerosity, we found similar percentages between patients with a history of spontaneous delivery and patients with previous Caesarean section. In 48 patients with a diastasis only above the navel, $8 \%$ had no history of delivery, $56 \%$ had a previous spontaneous delivery, and $35 \%$ had a previous Caesarean section. In 24 patients with a diastasis complete but wider above the navel, $4 \%$ were nulliparous, $58 \%$ had history of spontaneous delivery, and $37.5 \%$ had history of Caesarean section.

Eleven out of the 82 patients (13.4\%) were undergoing $\mathrm{CT}$ imaging. In no case did CT categorise a different diastasis pattern in comparison with US. The difference in diastasis measurements between US and CT was $0-9 \mathrm{~mm}$ (mean, $4 \mathrm{~mm}$ ). Also, seven out of the 82 patients $(8.5 \%)$ underwent MRI. MRI did not categorise a different pat-
Table 1. Demographic data in our study population

\begin{tabular}{|c|c|}
\hline Number of consecutive patients included & 92 \\
\hline Number of patients with diastasis & 82 \\
\hline Gender & All females \\
\hline Age of patients with diastasis & 30-51 years old (mean, 35$)$ \\
\hline Parity in patients with diastasis & $\begin{array}{l}5 / 82(6 \%) \text { nulliparous } \\
77 / 82(94 \%) \text { with previous } \\
\text { pregnancy } \\
\text { (1-4 pregnancies, mean 1.9) }\end{array}$ \\
\hline $\begin{array}{l}\text { Time from last delivery in patients with } \\
\text { diastasis }\end{array}$ & 8-62 months (mean, 14) \\
\hline \multicolumn{2}{|c|}{ Last delivery in patients with diastasis and pregnancy history } \\
\hline Spontaneous & $48 / 77(62.3 \%)$ \\
\hline Via Caesarean section & 29/77 (37.7\%) \\
\hline
\end{tabular}

tern compared to US in any case. The difference in diastasis measurements between US and MRI was $0-8 \mathrm{~mm}$ (mean, $3 \mathrm{~mm}$ ) (Figure 3).

\section{Discussion}

Diastasis recti is an aponeurotic laxity of the linea alba, with the muscles themselves that can be normal in thickness or, more frequently, atrophic (myoaponeurotic laxity) $[16,17]$. Below the navel the collagen fibres of the linea alba are arranged in a more transverse way, compared to their arrangement above the navel [18]. This basically accounts for the findings in our series. The novelty of the current study is that we provided an in vivo confirmation of this knowledge, providing statistical data on the prevalence of the different anatomical patterns. During pregnancy, the geometry of abdominal muscles changes, still maintaining their function [2]. After the delivery there is a physiological reduction of the recti muscles' thickness and an increase in the normal distance between the two muscles. This change usually persists for some months but, normally, within one year from the delivery the distance between the two muscles returns to the nor- 
Table 2. Prevalence and severity of the five diastasis patterns. Correlation with the modality of delivery

\begin{tabular}{|c|c|c|c|}
\hline Diastasis & No. (\%) & Width & Last delivery \\
\hline All patterns & $82(100 \%)$ & 21-97 mm (mean, 39) & $\begin{array}{c}\text { None } 5 / 82(6 \%) \\
\text { Spontaneous } 48 / 82(58.5 \%) \\
\text { Caesarean 29/82 (34.4\%) }\end{array}$ \\
\hline $\begin{array}{l}\text { Pattern } 1 \\
\text { (only above navel) }\end{array}$ & $48(58.5 \%)$ & 21-88 mm (mean, 40) & $\begin{array}{l}\text { None } 4 / 48(8.3 \%) \\
\text { Spontaneous } 27 / 48(56.25 \%) \\
\text { Caesarean 17/48 (35.4\%) }\end{array}$ \\
\hline $\begin{array}{l}\text { Pattern } 2 \\
\text { (only below navel) }\end{array}$ & $1(1.2 \%)$ & $33 \mathrm{~mm}$ & $\begin{array}{c}\text { None 0/1 } \\
\text { Spontaneous 1/1 (100\%) } \\
\text { Caesarean 0/1 }\end{array}$ \\
\hline $\begin{array}{l}\text { Pattern } 3 \\
\text { (at navel level) }\end{array}$ & $7(8.5 \%)$ & 23-39 mm (mean, 34) & $\begin{array}{c}\text { None 0/7 } \\
\text { Spontaneous 5/7 (71.4\%) } \\
\text { Caesarean 2/7 (28.6\%) }\end{array}$ \\
\hline $\begin{array}{l}\text { Pattern } 4 \\
\text { (complete but wider above navel) }\end{array}$ & $24(29.3 \%)$ & 21-97 mm (mean, 41) & $\begin{array}{c}\text { None 1/24 (4.2\%) } \\
\text { Spontaneous 14/24 (58.3\%) } \\
\text { Caesarean 9/24 (37.5\%) }\end{array}$ \\
\hline $\begin{array}{l}\text { Pattern } 5 \\
\text { (complete but wider below navel) }\end{array}$ & $2(2.4 \%)$ & $21-29$ mm (mean, 25) & $\begin{array}{c}\text { None } 0 \\
\text { Spontaneous } 1 / 2(50 \%) \\
\text { Caesarean } 1 / 2(50 \%)\end{array}$ \\
\hline
\end{tabular}
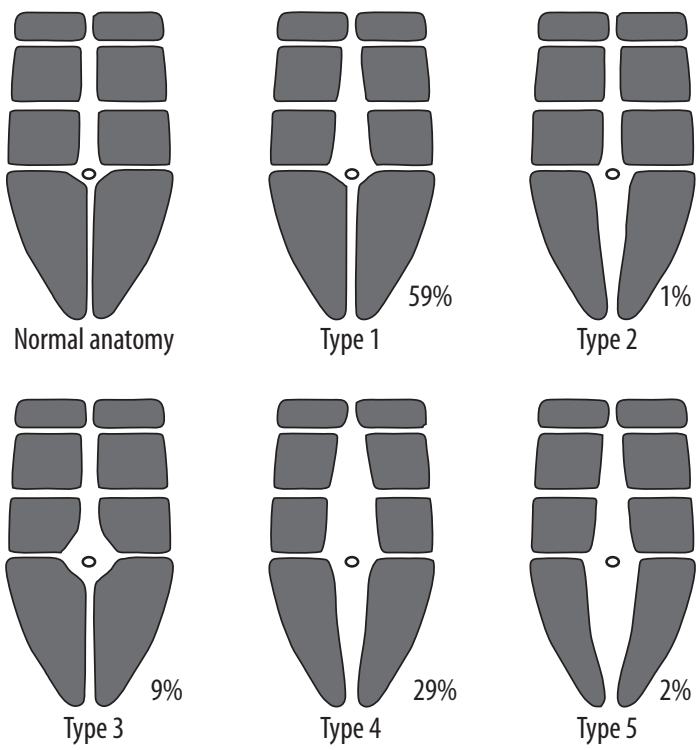

Figure 2. Schematic drawing of the prevalence of recti muscle diastasis according to the five anatomical patterns categorised in this study mal, pre-pregnancy value. In primiparous women, the inter-rectal distance may be considered "normal" up to values wider than in nulliparous [19].

There is no consensus of opinion regarding the normal distance between the rectus muscles. Only a few studies have evaluated the abdominal muscles in normal women and defined rectus diastasis. Beer et al. studied 159 healthy nulliparous women aged between 20 and 45 years with body mass index below 30 [20]. According to the Beer classification, the surgical definition of an abnormal inter-rectal distance is a width larger than $22 \mathrm{~mm}$ when measured $3 \mathrm{~cm}$ above the navel and larger than $16 \mathrm{~mm}$ when measured $2 \mathrm{~cm}$ below the navel [20]. In one study, the normal inter-rectal distance in primiparous women investigated 12 weeks after partum was found to be $26 \mathrm{~mm}$ when measured $2 \mathrm{~cm}$ above the navel and $11 \mathrm{~mm}$ when measured $2 \mathrm{~cm}$ below the navel [21]. In another article the normal inter-rectal distance $2 \mathrm{~cm}$ above the navel was established to be $15 \mathrm{~mm}$ in post-partum women and $10 \mathrm{~mm}$ in nullip-
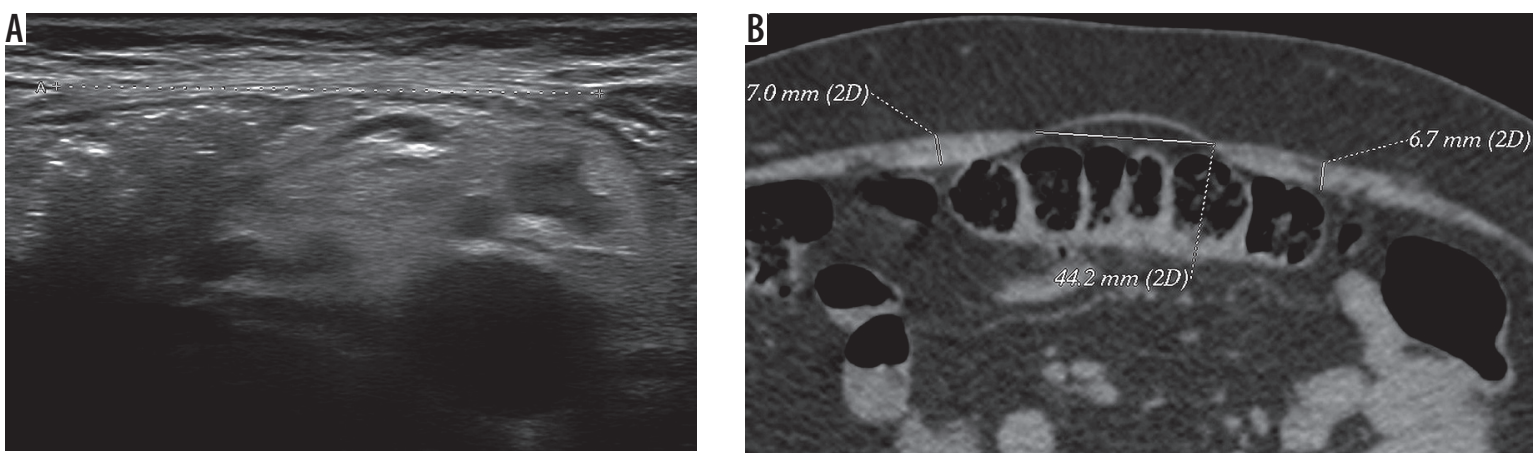

Figure 3. Thirty-year-old woman with one previous pregnancy. A) Longitudinal ultrasound image showing a $42 \mathrm{~mm}$ diastasis below the navel. B) Unenhanced axial computed tomography scan at the same level demonstrating a $44 \mathrm{~mm}$ diastasis. Recti muscles thickness also measured (7 mm for both) 
arous women [22]. However, a recent study showed that the normal width of the linea alba changes during pregnancy and in the post-partum period, depending also on the level of the US scan [19]. During pregnancy, the normal range of values, i.e. the $20^{\text {th }}$ and the $80^{\text {th }}$ percentile, correspond to 49 $79 \mathrm{~mm}$ below the umbilicus, $54-86 \mathrm{~mm}$ at $2 \mathrm{~cm}$ above the umbilicus, and $4-79 \mathrm{~mm}$ at $5 \mathrm{~cm}$ above the umbilicus. At six months postpartum, the $20^{\text {th }}$ and the $80^{\text {th }}$ percentiles corresponded to $9-21 \mathrm{~mm}$ at $2 \mathrm{~cm}$ below the umbilicus, from 17 to $28 \mathrm{~mm}$ at $2 \mathrm{~cm}$ above the umbilicus, and from 12 to 24 $\mathrm{mm}$ at $5 \mathrm{~cm}$ above the umbilicus [19]. It is also our experience that the distance is almost never uniform all along the linea alba. Our study supplies statistical information on the various anatomical patterns encountered in clinical practice, showing that some of them are more common than others.

Patients with diastasis recti must also be investigated for the concomitant presence of median line hernias. This is done both at rest and during the Valsalva manoeuvre (Figure 4). At the same time, a diastasis may clinically mimic a ventral hernia, particularly during the Valsalva test $[10,23]$. A diastasis should be excluded before an abdominal wall liposuction procedure, to avoid complications
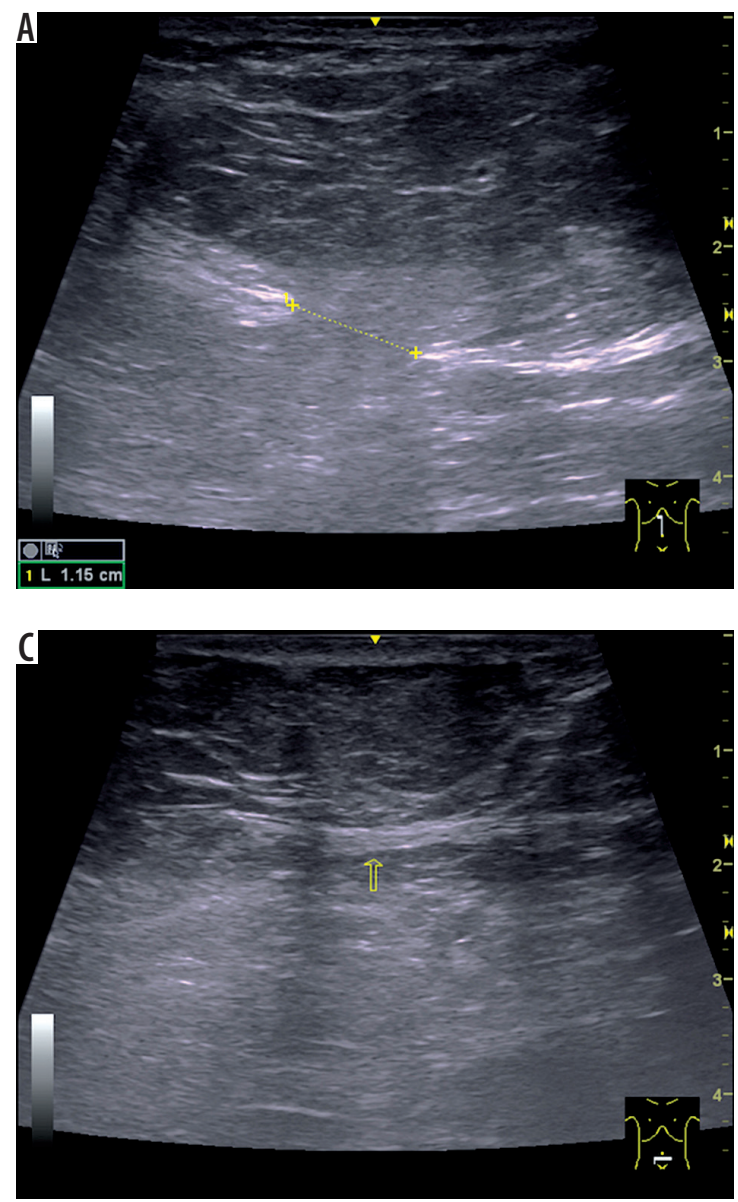

involving the abdominal content and particularly the bowel loops [24].

According to a recent meta-analysis, the available information supports US as an adequate method to assess diastasis of the recti abdominis muscles [25]. US measurement of inter-rectal distance has proven to have good to excellent intraobserver (both test-retest and between sessions) and interobserver reproducibility, particularly in the above-navel level of the abdominal wall [26-28]. In comparison with intra-operative findings also, US measurement has proven reliable, particularly in the above-navel area, while at the below-navel level there is a slight tendency to underestimate the separation between the two muscles [24,29]. The same applies to MRI [30] measurements and to CT [31] measurements, both of which underestimate somehow the extent of muscles separation $[32,33]$. The minor discrepancies found between pre-operatory measures, including imaging modalities other than US, and intra-operatory measures are possibly due to the muscle tone relaxation during general anaesthesia [32].

A pathological diastasis does not necessarily require repair, and conservative management may be an alterna-
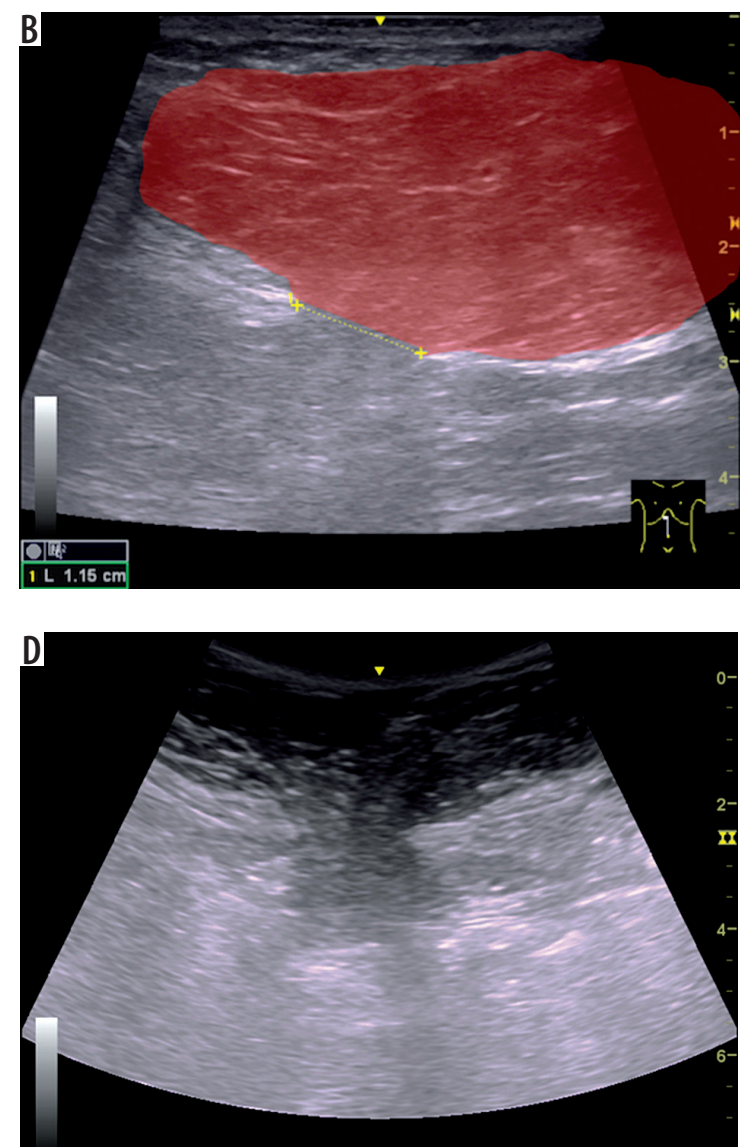

Figure 4. Forty-one-year-old woman with three previous pregnancies. A) Longitudinal ultrasound (US) image obtained using a linear probe demonstrates a large, fat-containing, non-reducible epigastric hernia arising from a tear that is located near on the linea alba. Note also that the neck (11.5-mm, defect in the linea alba), is narrow in comparison to the hernial fundus. B) Schematic interpretation of the same image, in which the hernial sac is shown in red (in transparency). C) Transverse US image below the navel shows the linea alba in that location, thinned; no tears are demonstrable on US. D) Corresponding image of the epigastric hernia obtained using a using a convex, which allows a greater panoramic view 
tive $[2,4]$. As proven through US observations, the interrectus distance can be reduced by isometric contraction of the abdominal muscles, with the subject actively performing an abdominal crunch (crook lying position) [22]. Conversely, the drawing-in exercise, which mainly activates the transverse abdominal and internal oblique muscles, seems to be ineffective in improving diastasis [21]. Surgical repair is mostly done due to aesthetic reasons, and it is basically reserved for severe cases, larger than $5 \mathrm{~cm}$, or when there is an associated hernia [1].

Our study has some limitations. First, the number of patients could have been larger. Second, we did not have a reference standard, and the presence and extent of diastasis in our US series had no independent verification. A minority of our patients also underwent CT or MRI, some others had abdominoplasty, but the vast majority of cases only had a US diagnosis. In this small group of patients there was no significant difference in terms of pattern categorisation and of diastasis severity measurement between US and CT/MRI. US has proven effective in var- ious published series in measuring the width of diastasis recti, also with a good correlation with surgery $[24,26,28]$.

\section{Conclusions}

The above-navel patterns of rectus abdominis muscle diastasis are by far the most common ones. Even when open completely, diastasis is usually wider above the navel. Knowledge of the anatomical type of rectus muscle diastasis could be interesting both to the patient (exercises to do and exercises to avoid) and to the surgeon (abdominoplasty approach planning, decision to insert or not insert a mesh, choice of the mesh type and size, etc.). In particular, establishing in each patient the anatomical pattern of diastasis may allow the development of tailored postnatal exercise programs.

\section{Disclosure}

The authors declare no conflicts of interest.

\section{References}

1. Akram J, Matzen SH. Rectus abdominis diastasis. J Plast Surg Hand Surg 2014; 48: 163-169.

2. Michalska A, Rokita W, Wolder D, et al. Diastasis recti abdominis a review of treatment methods. Ginekol Pol 2018; 89: 97-101.

3. Coldron Y, Stokes MJ, Newham DJ, et al. Postpartum characteristics of rectus abdominis on ultrasound imaging. Man Ther 2008; 13: 112-121.

4. Litros K. Progressive therapeutic exercise program for successful treatment of a postpartum woman with a severe diastasis recti abdominis. J Womens Health Phys Ther 2014; 38: 58-73.

5. Weis CA, Nash J, Triano JJ, et al. Ultrasound assessment of abdominal muscle thickness in women with and without low back pain during pregnancy. J Manipulative Physiol Ther 2017; 40: 230-235.

6. Fernandes da Mota PG, Pascoal AG, Carita AI, et al. Prevalence and risk factors of diastasis recti abdominis from late pregnancy to 6 months postpartum, and relationship with lumbo-pelvic pain. Man Ther 2015; 20: 200-205.

7. Sperstad JB, Tennfjord MK, Hilde G, et al. Diastasis recti abdominis during pregnancy and 12 months after childbirth: prevalence, risk factors and report of lumbopelvic pain. Br J Sports Med 2016; 50: 1092-1096.

8. Corvino A, Catalano O, Corvino F, et al. Superficial temporal artery pseudoaneurysm: what is the role of ultrasound? J Ultrasound 2016; 19: 197-201

9. Corvino A, Sandomenico F, Setola SV, et al. Added value of contrast-enhanced ultrasound (CEUS) with Sonovue in the diagnosis of inferior epigastric artery pseudoaneurysm: report of a case and review of literature. J Ultrasound 2019; 22: 485-189.

10. Arend CF. Static and dynamic sonography for diagnosis of abdominal wall hernias. J Ultrasound Med 2013; 32: 1251-1259.

11. Ahn SE, Park SJ, Moon SK, et al. Sonography of abdominal wall masses and masslike lesions: correlation with computed tomography and magnetic resonance imaging. J Ultrasound Med 2016; 35: 189-208.
12. Catalano O, Alfageme Roldán F, Varelli C, et al. Skin cancer: findings and role of high-resolution ultrasound. J Ultrasound 2019; 22: 423-431.

13. Corvino A, Sandomenico F, Corvino F, et al. Utility of gel standoff pad in the detection of Doppler signal on focal nodular lesions of the skin. J Ultrasound 2019; doi: 10.1007/s40477-019-00376-3 [Epub ahead of print].

14. Corvino A, Catalano O, Setola SV, et al. Contrast-enhanced ultrasound in the characterization of complex cystic focal liver lesions. Ultrasound Med Biol 2015; 41: 1301-1310.

15. Corvino A, Catalano O, Corvino F, et al. Diagnostic performance and confidence of contrast-enhanced ultrasound in the differential diagnosis of cystic and cysticlike liver lesions. AJR Am J Roentgenol 2017; 209: W119-W127.

16. Keshwani N, Mathur S, McLean L. Validity of inter-rectus distance measurement in postpartum women using extended field-of-view ultrasound imaging techniques. J Orthop Sports Phys Ther 2015; 45: 808-813.

17. Weis CA, Triano JJ, Barrett J, et al. Ultrasound assessment of abdominal muscle thickness in postpartum vs nulliparous women. J Manipulative Physiol Ther 2015; 38: 352-357.

18. Axer H, Keyserlingk DG, Prescher A. Collagen fibers in linea alba and rectus sheaths. I. General scheme and morphological aspects. J Surg Res 2001; 96: 127-134.

19. Mota P, Pascoal AG, Carita AI, et al. Normal width of the inter-recti distance in pregnant and postpartum primiparous women. Musculoskelet Sci Pract 2018; 35: 34-37.

20. Beer GM, Schuster A, Seifert B, et al. The normal width of the linea alba in nulliparous women. Clin Anat 2009; 22: 706-711.

21. Sancho MF, Pascoal AG, Mota P, et al. Abdominal exercises affect inter-rectus distance in postpartum women: a two-dimensional ultrasound study. Physiotherapy 2015; 101: 286-291. 
22. Pascoal AG, Dionisio S, Cordeiro F, et al. Inter-rectus distance in postpartum women can be reduced by isometric contraction of the abdominal muscles: a preliminary case-control study. Physiotherapy 2014; 100: 344-348.

23. Corvino A, Corvino F, Catalano O, et al. The tail and the string sign: new sonographic features of subcutaneous melanoma metastasis. Ultrasound Med Biol 2017; 43: 370-374.

24. De Almeida Mendes D, Xerfan Nahas F, Francescato Veiga D, et al. Ultrasonography for measuring rectus abdominis muscles diastasis. Acta Cir Bras 2007; 22: 182-186.

25. van de Water AT, Benjamin DR. Measurement methods to assess diastasis of the rectus abdominis muscle (DRAM): a systematic review of their measurement properties and meta-analytic reliability generalisation. Man Ther 2016; 21: 41-53.

26. Keshwani N, McLean L. Ultrasound imaging in postpartum women with diastasis recti: intrarater between-session reliability. J Orthop Sports Phys Ther 2015; 45: 713-718.

27. Keshwani N, Hills N, McLean L. Inter-rectus distance measurement using ultrasound imaging: does the rater matter? Physiother Can 2016; 68: 223-229.

28. Mota P, Pascoal AG, Sancho F, et al. Test-retest and intrarater reliability of 2-dimensional ultrasound measurements of distance between rectus abdominis in women. J Orthop Sports Phys Ther 2012; 42: 940-946.

29. Gunnarsson U, Stark B, Dahlstrand U, et al. Correlation between abdominal rectus diastasis width and abdominal muscle strength. Dig Surg 2015; 32: 112-116.

30. Corvino A, Sandomenico F, Setola SV, et al. Morphological and dynamic evaluation of complex cystic focal liver lesions by contrastenhanced ultrasound: current state of the art. J Ultrasound 2019; 22: 251-259.

31. Corvino A, Corvino F, Radice L, Catalano O. Synchronous mucinous colonic adenocarcinoma and multiple small intestinal adenocarcinomas: report of a case and review of literature. Clin Imaging 2015; 39: 538-542.

32. Emanuelsson P, Dahlstrand U, Strömsten U et al. Analysis of the abdominal musculo-aponeurotic anatomy in rectus diastasis: comparison of CT scanning and preoperative clinical assessment with direct measurement intraoperatively. Hernia 2014; 18: 465-471.

33. Elkhatib H, Buddhavarapu SR, Henna $\mathrm{H}$ et al. Abdominal musculoaponeuretic system: magnetic resonance imaging evaluation before and after vertical plication of rectus muscle diastasis in conjunction with lipoabdominoplasty. Plast Reconstr Surg 2011; 128: $733 e-40 e$ 